\title{
The impact of diagnostic delay on the course of acute appendicitis
}

\author{
V C Cappendijk, F W J Hazebroek
}

\begin{abstract}
Background-The diagnosis of acute appendicitis is often delayed, which may complicate the further course of the disease.

Aims-To review appendectomy cases in order to determine the incidence of diagnostic delay, the underlying factors, and impact on the course of the disease.

Methods-Records of all children who underwent appendectomy from 1994 to 1997 were reviewed. The 129 cases were divided into group A (diagnostic period within 48 hours) and group $B$ (diagnostic period 48 hours or more).

Results-In the group with diagnostic delay, significantly more children had first been referred to a paediatrician rather than to a surgeon. In almost half of the cases in this group initial diagnosis was not appendicitis but gastroenteritis. The perforation rate in group $A$ was $24 \%$, and in group $B, 71 \%$. Children under 5 years of age all presented in the delayed group $B$ and had a perforation rate of $82 \%$. The delayed group showed a higher number of postoperative complications and a longer hospitalisation period.

Conclusions-Appendicitis is hard to diagnose when, because of a progressing disease process, the classical clinical picture is absent. The major factor in diagnostic delay is suspected gastroenteritis. Early surgical consultation in a child with deteriorating gastroenteritis is advised. Ultrasonographs can be of major help if abdominal signs and symptoms are non-specific for appendicitis. (Arch Dis Child 2000;83:64-66)
\end{abstract}

Keywords: appendicitis; gastroenteritis; diagnostic delay; non-specific symptoms

As noted by Hutson and Beasley: "Abdominal pain is extremely common in children and may reflect a variety of conditions. Whenever it lasts for more than four to six hours and gets more intense, or is associated with persistent vomiting or prolonged diarrhoea, it must be taken seriously, and a surgical cause ought to be excluded first". The most common cause of acute abdomen in children is acute appendicitis, but its diagnosis can present significant difficulties. Particularly in the very young the history and physical examination may be difficult, which often causes "diagnostic delay" before appendicitis is eventually diagnosed. ${ }^{23}$ Diagnostic delay could well result in a complicated disease process. ${ }^{45}$$$
\text { disease process. }{ }^{45}
$$

We performed a retrospective study to establish the incidence of diagnostic delay in children admitted to our hospital in which ultimately the diagnosis of acute appendicitis was made. Delay is understood to have occurred when the diagnostic period exceeded the usual 48 hours. We also investigated the factors underlying diagnostic delay, and possible relations between diagnostic delay and the course of the disease.

\section{Patients and methods}

In the period 1994-97, 129 children underwent appendectomy in the Sophia Children's Hospital. The median age of the patients was 9 years (mean 8.8, range 1-17). There were 74 boys and 55 girls. A data collection form served to gather information on patient characteristics, referral pattern, presenting symptoms at initial visit, laboratory and radiological examinations, and time from onset to surgery. Details of the operative findings and postoperative courses were reviewed. All data were obtained from patients' medical records. Patients were classified into two groups according to length of the diagnostic period: less than 48 hours and 48 hours or more. The diagnostic period is the time elapsed between first complaints and definitive diagnosis. The diagnostic period therefore includes the period elapsed before seeking medical advise. A diagnostic period less than 48 hours is considered to be typical in the case of acute appendicitis. Differences between the groups were analysed using $\chi^{2}$ tests, and statistical significance was established at $\mathrm{p}<0.05$.

\section{Results}

In 51 patients the diagnostic period was shorter than 48 hours (group A). Definitive diagnosis was delayed more than 48 hours in 78 patients (group B: “delayed group”). Table 1 shows age distribution in both groups.

General practitioners had referred 46 of the 51 patients in group A primarily to the paediatric surgeon, versus 46 of the 78 patients in group $B(p<0.0001)$. The other patients (in both groups $A$ and $B$ ) had been primarily referred by general practitioners to a paediatrician. Those in group A were seen in the outpatient department, after which a (paediatric) surgeon was consulted. Most children in group

Table 1 Age distribution

\begin{tabular}{lllc}
\hline Age $(y)$ & Group $A$ & Group $B$ & Total \\
\hline $0-4$ & - & 11 & 11 \\
$4-8$ & 12 & 21 & 33 \\
$>8$ & 39 & 46 & 85 \\
Total & 51 & 78 & 129 \\
\hline
\end{tabular}

Correspondence to: Dr Hazebroek email: hazebroek@chis.azr.n 
B first seen by a paediatrician were then admitted for further diagnostic procedures and treatment. Thirteen severe cases in group B were referred through a paediatrician in another hospital. Nine of them were first seen by a paediatrician and next by a surgeon.

Table 2 presents the admission diagnoses and length of delay of patients in group B. Appendicitis was not the primary diagnosis in 43 cases. The children in group A all had brief manifestations, starting with pain in the umbilical region which shifted to the right lower abdomen. Almost all had been nauseous and had vomited. Most of them had also had unmistakable peritoneal irritating signs localised in the right lower quadrant. Nature and course of the primary manifestations were rather diverse in the patients from group B, but included in almost all cases abdominal pain without distinct signs of peritonitis. Rectal examination was not performed routinely. Diarrhoea was noted in nine of the 51 patients in group $\mathrm{A}$, and in 38 of the 78 patients in group B $(p<0.0001)$.

Other non-specific symptoms, such as coughing, sore throat, dysuria, and obstipation were only seen sporadically, in both groups. In none of the patients from group A had non-specific symptoms-diarrhoea in nine of 51 , obstipation in one, and dysuria in threebeen interpreted as diagnosis: in all cases the admission diagnosis was acute appendicitis.

Most children who had been referred to our hospital through a paediatrician elsewhere had been treated for gastroenteritis. The four children who had been directly referred to a surgeon had unmistakable peritonitis shortly before referral. Peritonitis had not been recorded in the nine children referred by another hospital and first seen by a paediatrician in our hospital before surgical consultation followed and the diagnosis of appendicitis had been established.

At the time the diagnosis appendicitis was eventually made, almost all patients in group B had an "acute abdomen". Ultrasonography was the diagnostic tool of choice. In group A an ultrasound examination was made in 23 cases. In 21 of these the diagnosis of appendicitis could be established. The other two ultrasound examinations did not show appendicitis. In group B an ultrasound examination was made in 57 cases and showed the typical features of appendicitis in 46. In seven the diagnosis of appendicitis could not been made. In four the radiologist was in doubt about the correct diagnosis. When the diagnosis of appendicitis was established, antibiotics were started in both groups.

Table 2 Admission diagnoses and diagnostic delay in group $B$

\begin{tabular}{lrrrr}
\hline & \multicolumn{4}{c}{ Diagnostic delay (days) } \\
\cline { 2 - 5 } Diagnosis & $2-5$ & $5-9$ & $>9$ & Total \\
\hline Appendicitis & 26 & 7 & 2 & 35 \\
Gastroenteritis & 29 & 7 & 2 & 38 \\
Constipation & 1 & 1 & 0 & 2 \\
Urinary tract infection & 2 & 1 & 0 & 3 \\
Total & 58 & 16 & 4 & 78 \\
\hline
\end{tabular}

Table 3 Perforations in each age category

\begin{tabular}{llrl}
\hline Age $(y)$ & Group $A$ & \multicolumn{1}{c}{ Group B } & \multicolumn{1}{c}{ Total } \\
\hline $0-4$ & - & $9 / 11(82 \%)$ & $9 / 11(82 \%)$ \\
$4-8$ & $5 / 12(42 \%)$ & $15 / 21(71 \%)$ & $20 / 33(61 \%)$ \\
$>8$ & $7 / 39(18 \%)$ & $31 / 46(67 \%)$ & $38 / 85(45 \%)$ \\
Total & $12 / 51(24 \%)$ & $55 / 78(71 \%)$ & $67 / 129(52 \%)$ \\
\hline
\end{tabular}

Table 4 Hospitalisation period related to perforated or non-perforated appendicitis

\begin{tabular}{llll}
\hline & Non-perforated & Perforated & Total \\
\hline Group A & $4.3(2-12)$ & $7.4(4-18)$ & $5.0(2-18)$ \\
Group B & $5.3(3-12)$ & $9.7(3-43)$ & $8.4(3-43)$ \\
\hline
\end{tabular}

Results expressed as mean (range) in days.

Perforation was observed in 67 of the 129 children. When differentiated by age, perforation is more common, though not significantly so, in younger children, both in group A and group B (see table 3). Perforations were significantly more frequent in group B compared to group A: 55 of 78 and 12 of 51 respectively $(\mathrm{p}<0.001)$. This was associated with a higher number of postoperative complications: six of 51 in group A, and 20 of 78 in group B $(\mathrm{p}=0.09)$.

Two children from group A with nonperforated appendix had a wound abscess. Of those cases with perforated appendix in group A, two had a wound abscess and two had postoperative paralytic ileus. Wound abscess was observed in five children with non-perforated appendix in group B, and in 13 with perforated appendix in group B. The latter group also included a patient with enterocutaneous fistula and a patient with abdominal infectious complications with sepsis, necessitating ventilatory support. The latter two patients were operated on several times.

Table 4 presents length of hospitalisation and differences between groups with or without perforation. In the delayed diagnosis group (B), hospitalisation was a mean 3.4 days longer.

\section{Discussion}

Whenever a child presents with pain in the umbilical region shifting to the right lower abdomen within 24 hours, nausea and vomiting, pain on transportation, and local peritoneal irritation at physical examination, the diagnosis of acute appendicitis is clear. This situation applies to the patients in group $\mathrm{A}$ in this study. The diagnosis of acute appendicitis is often complicated, however, by non-specific symptoms. ${ }^{5-7}$ Intermittent abdominal complaints and parental delay have also been described to cause diagnostic delay. ${ }^{8}$

Group A in this study does not include children aged 1-4 years. All children in this age category presented in the delayed diagnosis group B. In total, $60 \%$ of all children belonged to group B. Children in this group had significantly more frequently been referred to a paediatrician first, which indicates that the clinical picture in this group was often not indicative of classical appendicitis. However, they were so severely ill, mostly from gastroenteritis, that admission was indicated. At a deteriorating stage of the disease, both general practitioner 
and paediatrician ought to shorten their observation period and consult a surgeon. ${ }^{9}$ Thus the general practitioner will compensate for the parental delay, and the paediatrician for the professional delay, provided that the surgeon is making the correct diagnosis. ${ }^{10}$

Diarrhoea was quite common in both groups, in group B significantly more than in group A. Diarrhoea resulted in the diagnosis of gastroenteritis in almost half of the cases in group B, and greatly influenced the diagnostic delay. The impact of diarrhoea as a confusing symptom in making the diagnosis of acute appendicitis has been described previously. ${ }^{411}{ }^{12}$ Gamal et $a l^{13}$ present a table showing that diarrhoea is very often a concomitant symptom in appendicitis, but fail to acknowledge this as a significant symptom. The differential diagnosis of acute abdominal pain in children is comprehensive. ${ }^{1}$ Nevertheless, it is usually quite possible to distinguish between the different clinical pictures and acute appendicitis, with the exception of a "common" frequent gastroenteritis. Major differences between a viral gastroenteritis and appendicitis are the profuse watery diarrhoea in gastroenteritis, and the much more severe progressive abdominal pain in appendicitis. In addition, viral gastroenteritis is often associated with respiratory tract infection.

Diarrhoea in this study was not always a "small amount of loose stools", as described by Horwitz et $a l^{4}$ but also regularly watery diarrhoea. The distinction between watery and gruel like diarrhoea, however, does not always stand out in this retrospective study. More importantly, the diagnosis of gastroenteritis should not be resorted to as a refuge diagnosis, as referred to by Rusnak et al. ${ }^{14}$ They report that gastroenteritis is often mentioned as discharge diagnosis, even though the medical records often did not include data pointing at this.

Risk of perforation will greatly increase with time. Table 3 clearly shows that young children also have increased risk of perforation.

The number of complications was higher in group B, though not significantly so. Some of these complications were severe and necessitated reoperation. The higher number of complications in group B is responsible for the fact that in this group hospitalisation is a mean 3.4 days longer than in group A.

If appendicitis is deduced from the differential diagnosis, but clinical signs are not explicit, ultrasonography is the imaging technique of choice, because of its high sensitivity and specificity. ${ }^{15-20}$ However, in the case of a perforation, ultrasonography will not always enable a decisive conclusion to be made. Accumulation of fluid in the lumen of an enlarged and incompressible appendix is a major finding in the case of a non-perforated appendix. Local- ised periappendicular fluid accumulations make a perforated appendix quite plausible.

In conclusion, appendicitis is hard to diagnose when, on account of a progressing disease process, the classical picture of appendicitis is absent. As appears from the literature and this study, the factors determining the diagnostic delay are numerous and often cannot be influenced. From this study it appears that the influence of the symptom diarrhoea is insufficiently recognised. Diagnostic delay means an increase of complications and consequently a prolonged hospitalisation period.

Therefore, in a child with abdominal complaints, which do not settle quickly, appendicitis should be excluded by early and if necessary repeated surgical consultations irrespective of associated symptoms. When still in doubt, an ultrasound examination, focusing on the described specific characteristics of acute appendicitis and perforation is strongly recommended. The authors emphasise that in the case of a negative ultrasound examination and deteriorating abdominal complaints, the surgeon will decide to perform a diagnostic laparotomy.

1 Hutson JM, Beasley SW. The surgical examination of children. Oxford: Heinemann Medical Books, 1988:16-34.

2 Barker AP, Davey RB. Appendicitis in the first three years of life. Aust N Z 7 Surg 1988;58:491-4.

3 Williams N, Kapila L. Acute appendicitis in the under-5 year old. fR Coll Surg Edinb 1994;39:168-70.

4 Horwitz JR, Gursoy M, Jaksic T, et al. Importance of diarrhea as a presenting symptom of appendicitis in very young children. Am f Surg 1997;173:80-2.

5 Rappaport WD, Peterson M, Stanton C. Factors responsible for the high perforation rate seen in early childhood appendicitis. Am Surg 1989;55:602-5.

6 Wilson D, McCallion WA. Diagnostic delay in appendicitis. Br f Gen Pract 1995;45:326.

7 Reynolds SL. Missed appendicitis in a pediatric emergency department. Pediatr Emerg Care 1993;9:1-3.

8 Buchman GT, Zuidema GD. Reasons for delay of the diagBuchman GT, Zuidema GD. Reasons for delay of the diag-
nosis of acute appendicitis. Surg Gynecol Obstet 1984;158: nosis of

9 Harrison MW, Lindner DJ, Campbell JR, et al. Acute appendicitis in children: factors affecting morbidity. $A m \mathcal{F}$ Surg 1984;147:605-10.

10 Brender JD, Marcuse EK, Koepsell TD, et al. Childhood appendicitis: factors associated with perforation. Pediatrics 1985;76:301-6.

11 Williams NMA, Johnstone JM, Everson NW. The diagnostic value of symptoms and signs in childhood abdominal pain F $R$ Coll Surg Edinb 1988;43:390-2.

12 Franklin AJ, Glaysher C. Acute appendicitis presenting as gastroenteritis in an infant. Br f Clin Pract 1973;27:21-2.

13 Gamal R, Moore TC. Appendicitis in children aged 13 years and younger. Am F Surg 1990;159:589-92.

14 Rusnak RA, Borer JM, Fastow JS. Misdiagnosis of acute appendicitis: common features discovered in cases after appendicitis: common features discovered in

15 Puylaert JBCM, Rutgers PH, Lalisang RI, et al. A prospective study of ultrasonography in the diagnosis of appendicitis. N Engl F Med 1987;317:666-9.

16 Ooms HWA, Koumans RKJ, Ho Kang You PJ, et al. Ultrasonography in the diagnosis of appendicitis. Br f Surg 1991;78:315-18.

7 Mason JD. The evaluation of acute abdominal pain in children. Emerg Med Clin North Am 1996;14:629-43.

18 Schulte B, Beyer D, Kaiser C, et al. Ultrasonography in suspected acute appendicitis in childhood-report of 1285 cases. Eur 7 Ultrasound 1998;8:177-82.

19 Lessin MS, Chan M, Catallozzi M, et al. Selective use of ultrasonography for acute appendicitis in children. $A m \mathcal{F}$ Surg 1999;177:193-6.

20 Rice HE, Arbesman M, Martin DJ, et al. Does early ultrasonography affect management of pediatric appendicitis? A prospective analysis. F Pediatr Surg 1999;34:754-9. 